\title{
Avaliação de I 66 etes em operação no País, COMPREENDENDO DIVERSAS TECNOLOGIAS. Parte 2 - InfluênCia de fatores de PROJeto e operação
}

\author{
EVALUATION OF I 66 TREATMENT PLANTS OPERATING IN BRAZIL, \\ COMPRISING SEVERAL TECHNOLOGIES. PART 2 - THE INFLUENCE OF \\ DESIGN AND OPERATIONAL PARAMETERS
}

\begin{abstract}
SÍLVIA M. A. CORRÊA OLIVEIRA
Engenheira eletricista.Mestre em Saneamento, Meio Ambiente e Recursos Hídricos pela UFMG.

Doutoranda na área de Saneamento na UFMG
\end{abstract}

\section{MARCOS VON SPERLING}

Doutor em Engenharia Ambiental pelo Imperial College, Universidade de Londres. Professor Adjunto do Departamento de Engenharia Sanitária e Ambiental - DESA da UFMG

Recebido: 28/01/05 Aceito: 20/10/05

\section{RESUMO}

O estudo avalia a influência de fatores de projeto e de operação no desempenho de estações de tratamento de esgotos, considerando a concentração efluente e eficiência de remoção de DBO. Apenas quatro das seis tecnologias de tratamento estudadas na Parte 1 forneceram dados suficientes para análise: lagoas facultativas, lagoas anaeróbias seguidas por lagoas facultativas, lodos ativados e reatores UASB operando isoladamente. O objetivo da pesquisa foi verificar a influência das condiçōes de carga (sobrecarga, carga adequada e subcarga), do porte da estação e do envolvimento operacional (tendo como indicador a frequiência de monitoramento) no desempenho das estaçōes de tratamento. Os resultados mostraram que não existe uma relação consistente entre a eficiência de remoção e as variáveis operacionais. A contribuição e a influência de cada variável difere de ETE para ETE, e pode ser resultado de projeto, operação ou ambos.

PALAVRAS-CHAVE: Qualidade de efluente, avaliação de desempenho, tratamento de esgotos domésticos.

\begin{abstract}
The paper analyses the performance of the wastewater treatment plants considering the influence of the design and operational parameters. Four different treatment technologies have been investigated, comprising the following processes: facultative pond, anaerobic pond + facultative pond, activated sludge, UASB reactors without post treatment. The objective of the research was to verify the influence of the loading conditions, plant's size and the operational quality (indicated by monitoring frequency) on the effluent quality. The results showed that a consistent relationship between performance and design and operational parameters does not exist. The contribution and influence of any variable differs for each plant. This situation may be a result of design, operation or both.
\end{abstract}

KEYWORDS: Effluent quality, performance evaluation, wastewater treatment.

\section{INTRODUÇÃO}

A primeira parte do trabalho, intitulada "Avaliação de 166 ETEs em operação no país, compreendendo diversas tecnologias. Parte 1: Análise de desempenho" (Oliveira e von Sperling, 2005) comparou o desempenho de seis modalidades de tratamento de esgotos, usualmente empregadas no Brasil. O desempenho das ETEs foi comparado, também, com valores de concentração efluente e eficiência de remoção reportados na literatura técnica para cada tecnologia de tratamento. Nessa segunda parte do trabalho é avaliada a influência de fatores de projeto e de operação no desempenho de 132 estaçôes de tratamento de esgotos, considerando a concentração efluente e a eficiência de remoção de DBO.

Sabe-se que, geralmente, não existe apenas uma variável responsável pela qualidade e variabilidade do efluente, que dependem de variações na carga afluente, das condiçōes ambientais nos reatores, da natureza do esgoto a ser tratado, da presença de substâncias tóxicas, da variabilidade inerente aos processos de tratamento biológico e de falhas mecânicas e humanas no sistema. Todos esses fatores podem levar a problemas e instabilidade nos processos, o que ocasionará efeitos adversos na qualidade do efluente. Vários estudos realizados por Niku et al (1979, 1981, 1982), Niku e Schroeder (1981), Crites \& Tchobanoglous (2000), Metcalf \& Eddy (2003), von Sperling e Chernicharo $(2000,2002)$ avaliaram diversos processos de tratamento de esgotos em termos da qualidade do efluente. Estes trabalhos, de uma maneira geral, avaliaram estaçôes de tratamento de esgotos bem monitoradas, ainda que nem sempre bem operadas, situação diferente 
da verificada no presente estudo. Aqui, além das dificuldades inerentes à avaliação de sistemas biológicos de tratamento, a falta de alguns dados técnicos de parâmetros de projeto e de operação dificultou ainda mais a obtenção de conclusões. No entanto, dentro das limitações que o número e a qualidade dos dados disponibilizados permitiram, o desempenho das tecnologias de tratamento foi avaliado em termos da qualidade do efluente gerado e da eficiência de remoção de DBO. Procurou-se verificar a existência de melhores resultados de desempenho quando os sistemas trabalhavam numa faixa recomendada para os parâmetros de projeto e operação. Diante da grande variabilidade do desempenho das ETEs, procurou-se checar ainda se eventuais bons ou maus desempenhos estariam relacionados a condiçôes de subcarga ou sobrecarga, respectivamente.

Não foi possível a manutenção das seis tecnologias estudadas no trabalho anterior (Parte 1) já que algumas não forneceram dados dos parâmetros de projeto e operação necessários ao estudo. Este foi o caso das modalidades de fossas sépticas seguidas de filtros anaeróbios $(\mathrm{FS}+\mathrm{FA})$ e dos reatores UASB seguidos de pós-tratamento (UASB+POS). Assim, apenas quatro das seis tecnologias de tratamento (132 ETEs) estudadas na Parte 1 forneceram dados suficientes para análise: (a) lagoas facultativas (LF), (b) lagoas anaeróbias seguidas por lagoas facultativas, também denominadas de sistemas australianos (LAN+LF), (c) lodos ativados (LA) e (d) reatores UASB operando isoladamente (UASB). Como citado na Parte 1 do presente artigo, os dados utilizados neste trabalho foram obtidos no âmbito do projeto URBAGUA, estudo contratado com a FINEP, de interesse para a Agência Nacional de Águas (ANA), concluído em outubro de 2003, com parceria entre a USP e a UFMG. As estaçôes de tratamento de esgotos situam-se nos estados de São Paulo e Minas Gerais.

\section{METODOLOGIA}

A avaliação das condiçôes operacionais foi efetuada para verificação da existência de uma correlação entre parâmetros de projeto e de operação e desempenho das estaçôes de tratamento. Os parâmetros foram calculados a partir de dados técnicos disponibilizados pelas ETEs e foram correlacionados com dados de concentraçóes efluentes de DBO e eficiência de remoção da DBO afluen- te. A ênfase dada à qualidade do efluente em termos de DBO deveu-se à importância do parâmetro, à facilidade de análise dos resultados, à grande disponibilidade de dados, por ser este o único constituinte presente em padróes de lançamento de todas as legislaçóes estaduais pesquisadas e ainda pelo fato de que todas as estações investigadas objetivavam a sua remoção. As quatro tecnologias estudadas foram avaliadas, portanto, considerando a influência das condiçôes de carga e das condiçōes de operação.

\section{Condições de carga}

Foi efetuada uma comparação entre carga medida e carga recomendada para projetos, para se verificar se condições de sobrecarga ou subcarga poderiam estar afetando o desempenho. A Tabela 1 apresenta as modalidades selecionadas para estudo, o número de ETEs avaliadas em cada tecnologia de tratamento e os parâmetros utilizados para comparação. Os parâmetros de literatura retratam faixas amplas, recomendadas para projeto, em virtude da diversidade de características do afluente e das condições climáticas na região de estudo. $\mathrm{O}$ parâmetro TDH foi incluído em quase todas as unidades de todos os processos, não pelo fato de ser um parâmetro de projeto explícito, mas por retratar condições de operação, além de ser possível seu cálculo para todos os sistemas.

O intervalo usual citado na Tabela 1 foi utilizado como referência para determinação das condições de operação dos processos de tratamento analisados. Quando, por exemplo, uma LF operava com uma taxa de aplicação superficial (Ls) acima do limite superior da faixa reportada (300 kg DBO/ha.dia), era considerada em sobrecarga. Caso operasse com uma taxa menor que o limite inferior (150 kg DBO/ha.dia), considerava-se a ETE em subcarga. No caso do tempo de detenção hidráulica (TDH), aplicava-se o raciocínio inverso, isto é, TDHs superiores ao valor máximo da faixa reportada indicavam subcarga. Este critério foi empregado para todos os parâmetros e todas as modalidades.

\section{Condições de operação}

- Influência do porte das estações: medida pela vazão afluente, dentro do pressuposto de que ETE maiores poderiam estar sendo mais bem acompanhadas, monitoradas e operadas. As ETEs foram divididas em dois grandes grupos dentro de cada modalidade. O primeiro considerou $50 \%$ daquelas que tratavam as maiores vazóes e no segundo foram agrupadas as ETEs consideradas de menor porte ( $50 \%$ restantes).

- Influência do nível de operação das estaçôes: na impossibilidade de se mensurar a qualidade do nível de operação de cada ETE, analisou-se, indiretamente, pelo nível de monitoramento, denominado índice de monitoramento (IM).Este índice considerou a relaçăo entre o número de amostras do constituinte efluente disponibilizado pela ETE e o número total de dias contidos no período de monitoramento. Este índice foi multiplicado por 365 para se ter uma base de comparação entre todos os sistemas, sendo expresso em número de amostras por ano. O mesmo critério foi utilizado para medir o nível de operação das ETEs, considerando o índice de monitoramento (IM) praticado pelas estaçôes. No primeiro grupo foram dispostas $50 \%$ das ETEs que possuíam um maior número de amostras coletadas por ano e no segundo as de menores IM (50\% restantes).

\section{RESULTADOS E DISCUSSÂO}

De posse dos parâmetros calculados, buscou-se efetuar uma comparação gráfica com os valores usuais de projeto encontrados na literatura. O ideal para descrever esta relação seria a utilização dos modelos matemáticos de cada processo, mas a escassez de dados, bem como a complexidade da análise para todo o elenco de estaçôes, inviabilizaram esta possibilidade. Os gráficos de dispersão obtidos para as diversas correlações foram apresentados, separadamente, para cada modalidade de tratamento.

\section{Lagoas facultativas}

A Figura 1 apresenta os gráficos obtidos para as correlações da taxa de aplicação superficial $\left(\mathrm{L}_{\mathrm{s}}\right)$ e do tempo de detenção hidráulica (TDH) com remoção de DBO afluente e com concentração de DBO efluente. São apresentados, também, na forma de linhas pontilhadas, os valores mínimos e máximos esperados para concentrações efluentes e eficiências para essa modalidade específica. Esta faixa foi extraída de uma tabela apresentada em von Sperling (2005) para diferentes tecnologias de tratamento de esgotos. 
Tabela I - Parâmetros de projeto e operação utilizados na avaliação das condições de carga

\begin{tabular}{|c|c|c|c|c|c|c|}
\hline \multirow[t]{2}{*}{ Modalidade } & \multirow{2}{*}{\multicolumn{2}{|c|}{$\begin{array}{l}\text { Nome de } \\
\text { referência }\end{array}$}} & \multirow{2}{*}{$\begin{array}{l}\text { No de } \\
\text { ETEs }\end{array}$} & \multicolumn{3}{|c|}{ Parâmetros } \\
\hline & & & & Tipo & Unidade & Intervalo usual \\
\hline \multirow{2}{*}{$\begin{array}{l}\text { Lagoas } \\
\text { facultativas }\end{array}$} & LF & - & 73 & $\mathrm{~L}_{s}$ - taxa de aplicação superficial & $\mathrm{kg} \mathrm{DBO/ha.dia}$ & $150-300$ \\
\hline & & & & TDH: tempo de detenção hidráulica & dias & $15-45$ \\
\hline \multirow{5}{*}{$\begin{array}{c}\text { Lagoas } \\
\text { anaeróbias } \\
+ \\
\text { Lagoas } \\
\text { facultativas }\end{array}$} & $\mathrm{LAN}+\mathrm{LF}$ & LAN & 38 & $\mathrm{~L}_{\mathrm{v}}:$ taxa de aplicação volumétrica & $\mathrm{kg} \mathrm{DBO} / \mathrm{m}^{3}$.dia & $0,10-0,35$ \\
\hline & & & & TDH: tempo de detenção hidráulica & dias & $3-6$ \\
\hline & & LF & 40 & $\mathrm{~L}_{\mathrm{s}}$ - taxa de aplicação superficial & $\mathrm{kg} \mathrm{DBO/ha.dia}$ & $150-300$ \\
\hline & & & & TDH: tempo de detenção hidráulica & dias & $15-45$ \\
\hline & & & & Relação A/M: alimento/microrganismos & $\mathrm{kgDBO} / \mathrm{kgSSVTA.d}$ & $0,3-0,8(\mathrm{LAC})^{(a)}$ \\
\hline \multirow[t]{8}{*}{ Lodos ativados } & LA & $\mathrm{TA}^{(c)}$ & 12 & & & $0,08-0,15(\mathrm{LAP})^{(\mathrm{b})}$ \\
\hline & & & & TDH: tempo de detenção hidráulica & horas & 6 a 8 (LAC) \\
\hline & & & & & & $16-24$ (LAP) \\
\hline & & & & TAH: taxa de aplicação hidráulica & $\left(\mathrm{m}^{3} / \mathrm{m}^{2} \cdot \mathrm{h}\right)$ & $0,67-1,33$ (LAC) \\
\hline & & $\mathrm{D} S^{(\mathrm{d})}$ & 9 & & & $0,33-0,67$ (LAP \\
\hline & & & & TAH: taxa de aplicação hidráulica & $\left(\mathrm{kgSSTA} / \mathrm{m}^{2} \cdot \mathrm{h}\right)$ & $4-6$ (LAC) \\
\hline & & & & & & $1-5$ (LAP) \\
\hline & & & & TDH: tempo de detenção hidráulica & horas & $6-9$ \\
\hline Reatores UASB & UASB & & 9 & v: velocidade ascensional & $\mathrm{m} / \mathrm{h}$ & $0,5-0,7$ \\
\hline \multicolumn{4}{|c|}{ (a) LAC - Lodos ativados convencional } & \multicolumn{2}{|c|}{ (c) TA - Tanque de aeração } & \\
\hline \multicolumn{4}{|c|}{ (b) LAP - Lodos ativados aeração prolongada } & \multicolumn{2}{|c|}{ (d) DS - Decantador secundário } & \\
\hline
\end{tabular}

Fonte: Adaptada de von Sperling (1997 e 2002); Chernicharo (1997)

Pela observação da Figura 1, concluiu-se que, quando as ETEs operavam em condiçôes de sobrecarga, existia uma tendência de elevação da concentração de DBO efluente, como era de se esperar. No entanto, valores bastante elevados de taxa de aplicação parecem não ter conduzido a uma deterioração expressiva da qualidade do efluente. Os valores de concentração estiveram, de uma maneira geral, muito acima das faixas reportadas na literatura. Foi observada, também, uma ausência de relação entre a eficiência de remoção de $\mathrm{DBO}$ e $\mathrm{L}_{s}$. As condiçōes de subcarga ou sobrecarga não mostraram ter grande influência no desempenho, já que eficiências de remoção dentro ou abaixo das faixas de referência foram verificadas para ETEs operando em quaisquer das situaçōes analisadas. No entanto, os únicos episódios de desempenho acima do limite superior da faixa reporta$\mathrm{da}$ (melhor desempenho) foram observados para LFs operando dentro da intervalo recomendado para $\mathrm{L}$. A influência do TDH no desempenho foi muito pequena, como pode ser observado nos gráficos. As ETEs que apresentaram as maiores concentrações efluentes, isto é, os piores desempenhos, operavam dentro das faixas recomendadas para $\mathrm{TDH}$.

A Tabela 2 apresenta os valores máximo, médio (em negrito) e mínimo de vazão afluente e do índice de monitoramento (IM) apresentados pelas lagoas facultativas. A Figura 2 mostra os gráficos das relaçôes entre os parâmetros que avaliam essas condiçõos de operação e a concentração de $\mathrm{DBO}$ efluente e a remoção de DBO afluente.

Pela observação da Tabela 2 e da Figura 2, nota-se que houve uma grande amplitude considerando os valores máximos e mínimos de vazão e de IM apresentados pelas lagoas. Mas, de uma maneira geral, as ETEs que tratavam uma vazão menor não tiveram desempenhos diferenciados daquelas consideradas de maior porte. Apenas uma ligeira tendência de maiores concentraçōes efluentes de DBO foram observadas para as LFs de pequeno porte.

$\mathrm{O}$ índice de monitoramento não pareceu ter alguma influência expressiva no desempenho das estações de tratamento, ao se analisar as concentrações efluentes. No entanto, as eficiências de remoção observadas para as ETEs com menor número de amostras coletadas foram ligeiramente inferiores.

\section{Lagoas anaeróbias seguidas por lagoas facultativas}

A avaliação foi baseada na verificação dos resultados de desempenho quando os sistemas trabalhavam na faixa recomendada para os parâmetros de projeto e operação (Tabela 1) para as lagoas anaeróbias e facultativas. Para as duas lagoas, foram verificadas ainda a eficiência de remoção e as concentrações efluentes obtidas quando as ETEs operavam dentro dos intervalos usuais propostos para TDH, além da influência da vazão e do índice de monitoramento. A Figura 3 apresenta os gráficos de dispersão para concentração de DBO efluente e eficiência de remoção da $\mathrm{DBO}$ afluente para as lagoas anaeróbias em função dos parâmetros $\mathrm{L}_{\mathrm{v}} \mathrm{eTDH}$.

A Figura 3 mostrou que foram observadas situaçōes sistemáticas de subcarga orgânica, ao se considerar as lagoas anaeróbias. Nenhuma lagoa excedeu a carga orgânica máxima recomendada. No entanto, estas observaçōes se basearam em 

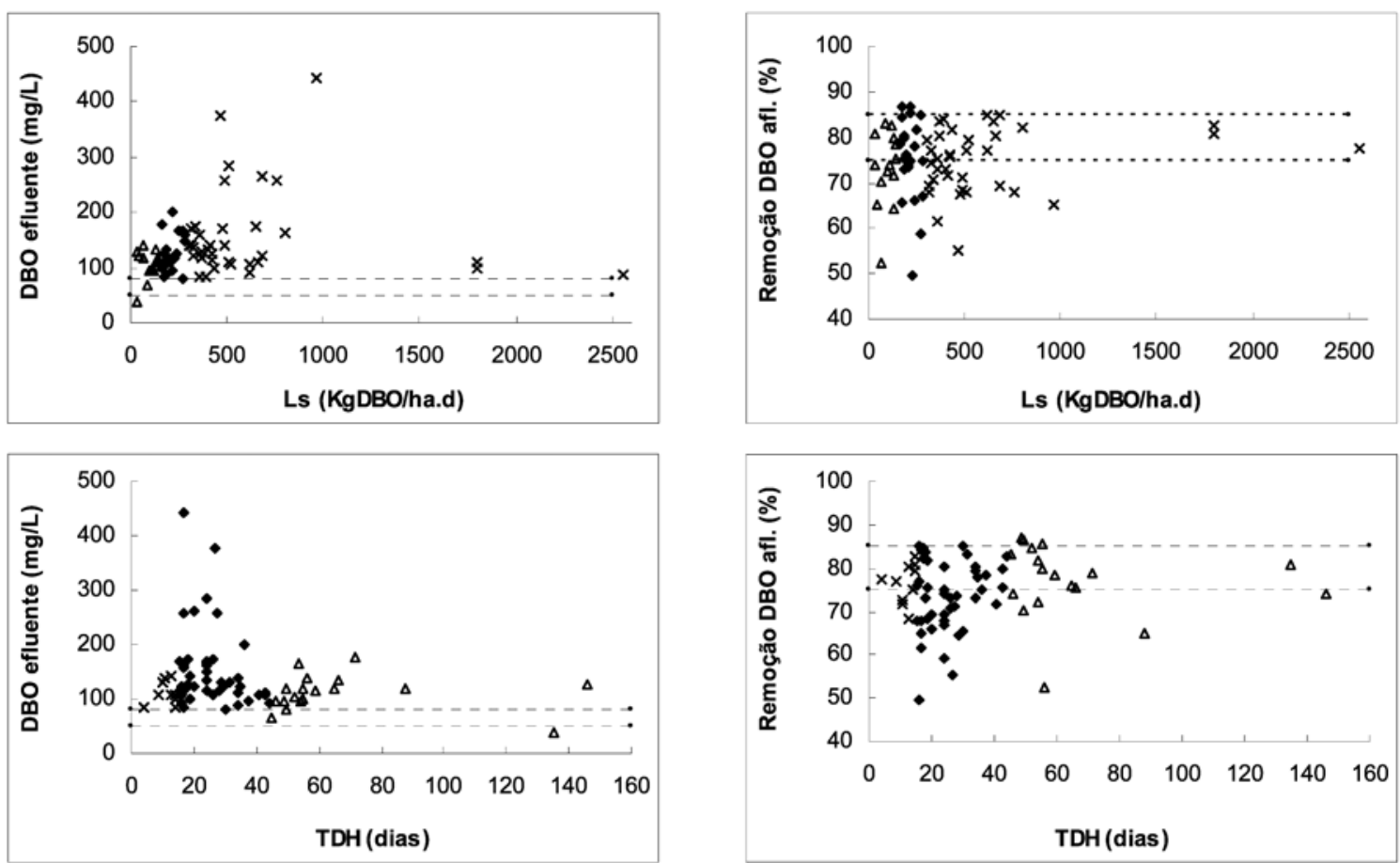

ETEs operando: $\triangle$ Subcarga

Faixa usual $X$ Sobrecarga

Nota: Faixas pontilhadas referem-se às concentrações de DBO e eficiências de remoção consideradas típicas pela literatura. Fonte: von Sperling, 2005.

Figura I - Relação entre Ls, TDH e concentração de DBO efluente e \% de remoção de DBO - LFs primárias

Tabela 2 - Valores máximos, médios e mínimos de Q afluente e IM-LFs primárias

\begin{tabular}{cccc}
\hline Parâmetros & Máximo & Médio & Mínimo \\
\hline Vazões $\left(\mathrm{m}^{3} /\right.$ dia $)$ & 4.689 & 462 & 4 \\
IM (n ${ }^{\circ}$ amostras/ano) & 19,4 & 3,2 & 0,6 \\
\hline
\end{tabular}

cálculos que consideraram as dimensões originais das lagoas, sendo possível que várias delas já estivessem com parte de seu volume útil ocupado por lodo, o que diminuiria o volume efetivamente disponível, ocasionando uma carga orgânica volumétrica real superior à calculada no trabalho.

Grande parte das lagoas funcionava com subcargas hidráulicas, ou seja, com tempos de detenção hidráulica bem acima do usual, mas isso não pareceu ter reflexo no desempenho observado.

A Tabela 3 apresenta os valores máximo, médio (em negrito) e mínimo de vazão afluente e do índice de monitoramento apresentados pelas lagoas anaeróbias e lagoas facultativas secundárias. As relações entre vazão $(\mathrm{Q})$ e índice de monitoramento (IM) e o desempenho das ETEs são mostradas na Figura 4.

Também nesse caso, foi observada uma grande amplitude considerando os valores máximos e mínimos de vazão e de IM apresentados pelas lagoas anaeróbias. No entanto, como mostra a Figura 4, não foi possível perceber uma influência expressiva da vazão no desempenho das lagoas anaeróbias. $\mathrm{O}$ índice de monitoramento, nesse caso, pareceu ter tido alguma influência, já que, de uma maneira geral, menores concentraçóes efluentes de DBO foram observadas para as ETEs com maiores IM. No entanto, para o maior IM praticado foi observado o pior desempenho.

As Figuras 5 e 6 apresentam os gráficos em função dos parâmetros $\mathrm{L}, \mathrm{TDH}$, vazão e IM para as lagoas facultativas secundárias.

A Figura 5 mostrou que a taxa orgânica aplicada não pareceu influir expressivamente no desempenho das LFs secundárias, sendo possível observar casos de eficiências muito baixas em situações de subcarga e de altas eficiências para
ETEs em sobrecarga. Observa-se que muitas lagoas operavam em condições de sobrecarga hidráulica, ou seja, TDH abaixo do valor recomendado. Apesar do mau desempenho de algumas ETEs em sobrecarga parecer ter sido influenciado por esta condição, observam-se casos de lagoas operando dentro dos intervalos usuais, sem uma boa eficiência correspondente. 6

Pela observação da Figura 6, não foi possível perceber uma influência expressiva da vazão e do índice de monitoramento no desempenho das lagoas facultativas secundárias.

\section{Lodos ativados}

A Figura 7 apresenta os gráficos de concentração de DBO e eficiência de remoção de DBO afluente em função da relação $\mathrm{A} / \mathrm{M}$ e do tempo de detenção hidráulica (TDH) no tanque de aeração.

Pela observação dos gráficos apresentados na Figura 7, verificou-se que o desempenho das ETEs da modalidade LA não foi afetado por diferentes relaçōes $\mathrm{A} / \mathrm{M}$ utilizadas. As condiçōes de subcarga ou sobrecarga não foram refletidas nos resultados de desempenho observados. As mesmas observações são válidas para o tempo de detenção hidráulica no tanque de aeração. 

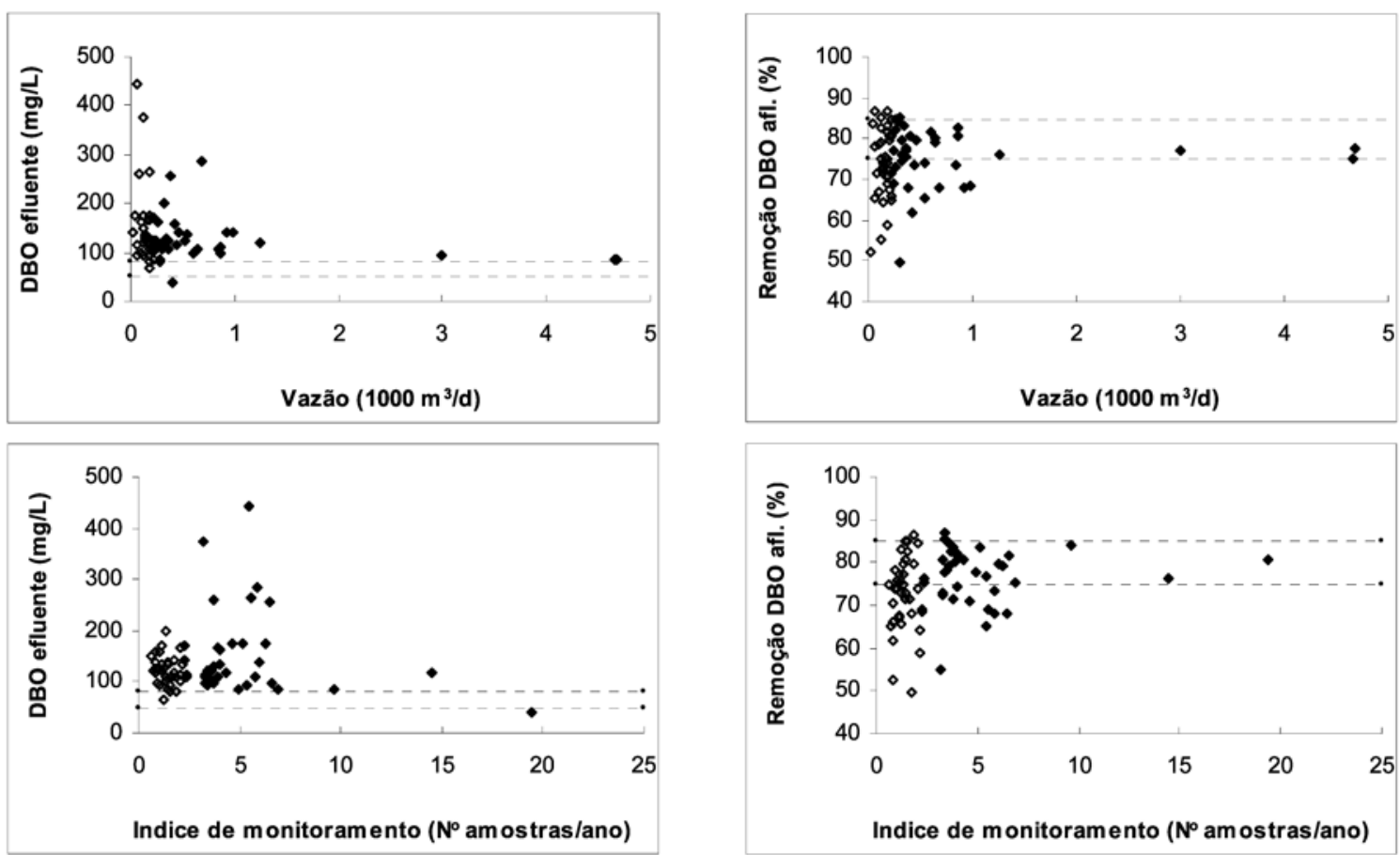

$\diamond$ Percentil $50 \%$ menores

Percentil $50 \%$ maiores

Nota: Faixas pontilhadas referem-se às concentrações de DBO e eficiências de remoção consideradas típicas pela literatura. Fonte: von Sperling, 2005.

Figura 2 - Relação entre Q e IM e concentração de DBO efluente e \% de remoção de DBO - LFs primárias
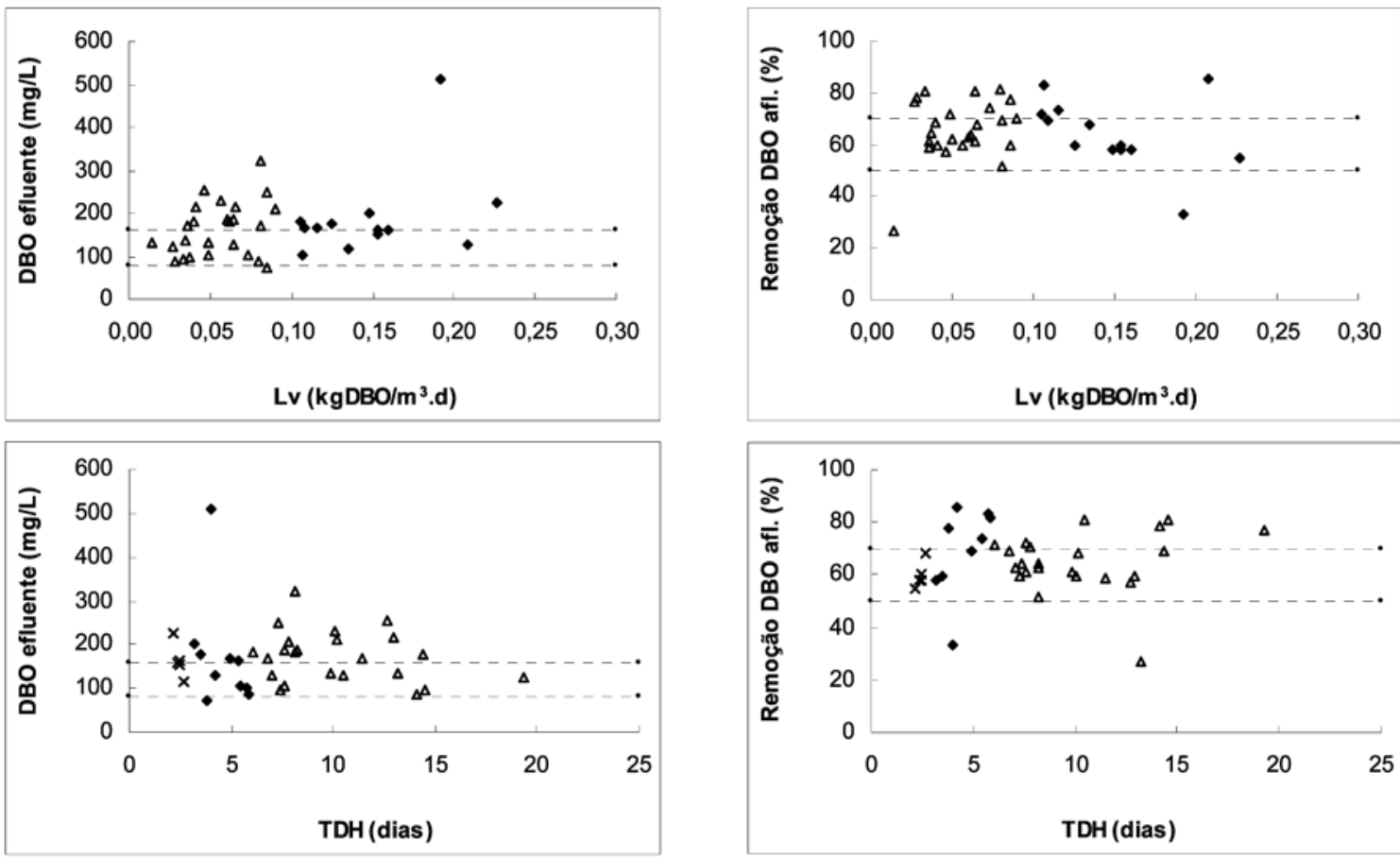

ETEs operando: $\triangle$ Subcarga

Faixa usual $\times$ Sobrecarga

Figura 3 - Relação entre Lv, TDH e concentração de DBO efluente e \% de remoção de DBO - LANs 
Tabela 3 - Valores máximos, médios e mínimos de Q afluente e IM - LANs e LFs secundárias

\begin{tabular}{cccc}
\hline Parâmetros & Máximo & Médio & Mínimo \\
\hline Vazões $\left(\mathrm{m}^{3} /\right.$ dia $)$ & 9.742 & $\mathbf{1 . 7 9 3}$ & 173 \\
$\mathrm{IM}\left(\mathrm{n}^{\circ}\right.$ amostras/ano) & 25,8 & $\mathbf{3 , 6}$ & 0,7 \\
\hline
\end{tabular}
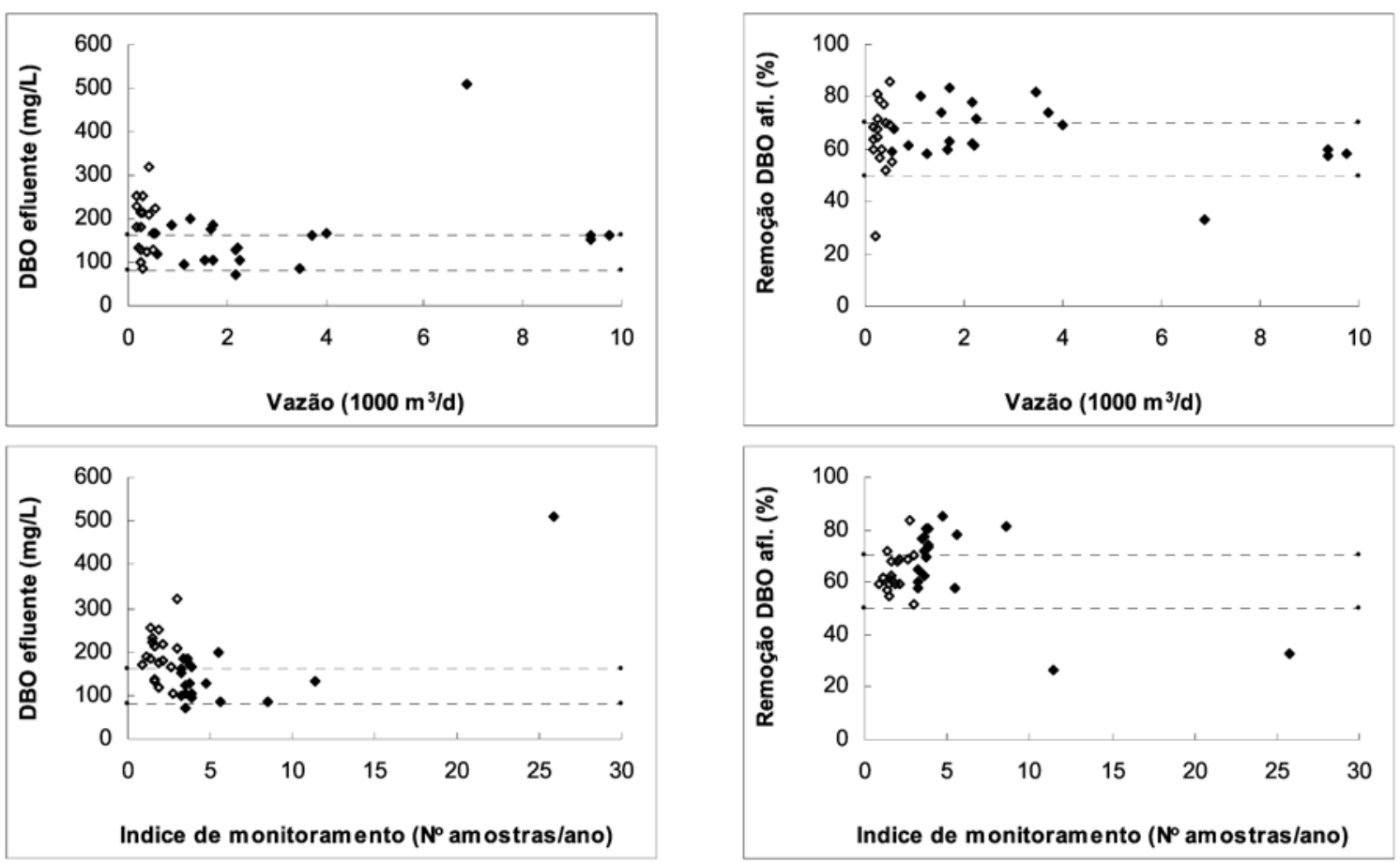

$\diamond$ Percentil $50 \%$ menores

Percentil $50 \%$ maiores

Figura 4 - Relação entre Q e IM e concentração de DBO efluente e \% de remoção de DBO - LANs
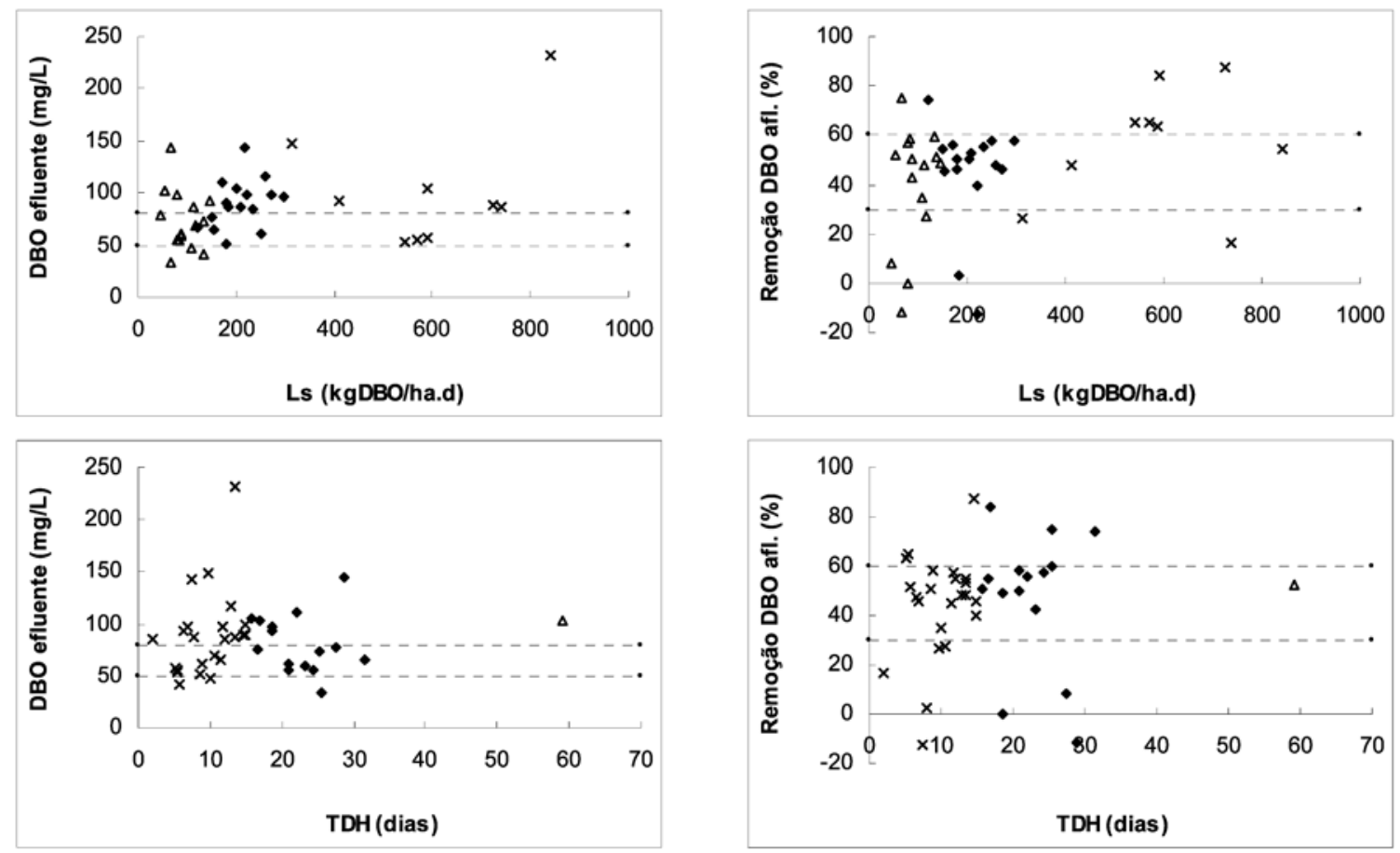

ETEs operando: $\triangle$ Subcarga

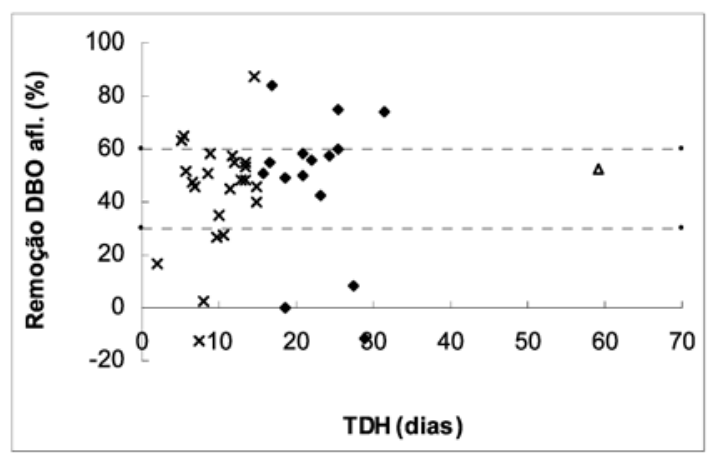

Faixa usual $X$ Sobrecarga

Figura 5 - Relação entre Ls, TDH e concentração de DBO efluente e \% de remoção - LFs secundárias 

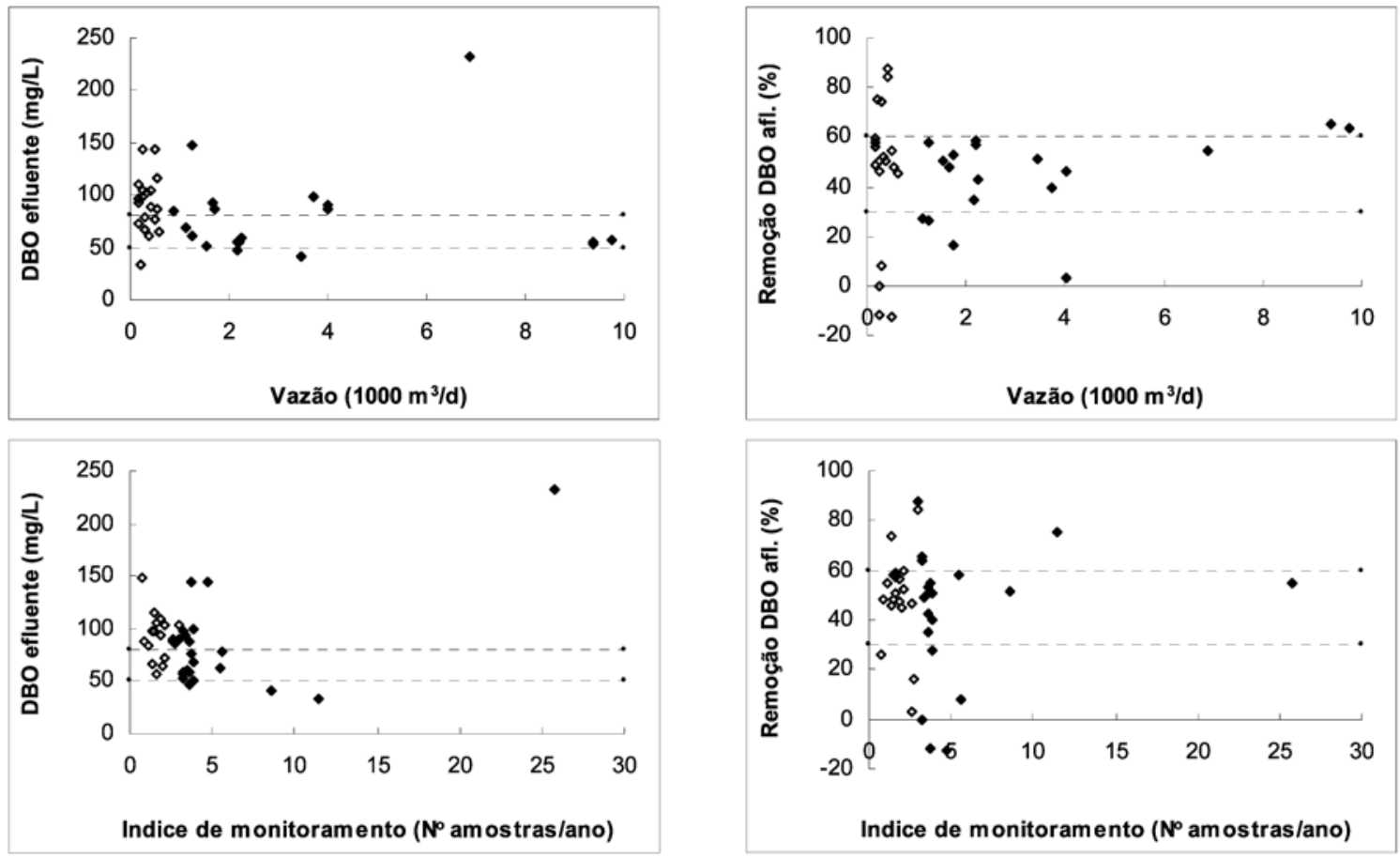

Percentil 50\% menores

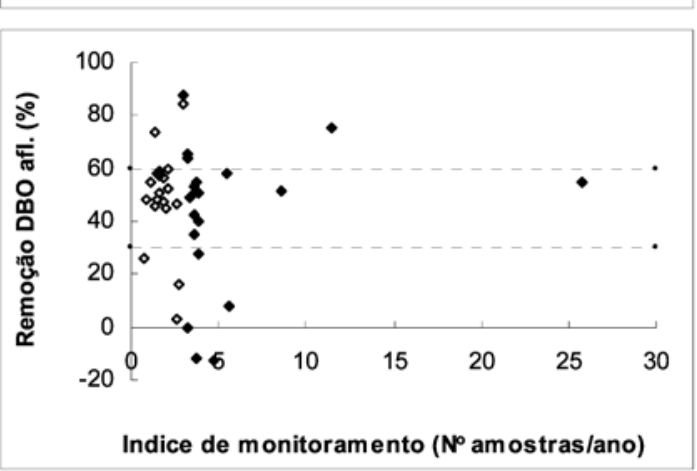

Percentil 50\% maiores

Figura 6 - Relação entre Q e IM e concentração de DBO efluente e \% de remoção - LFs secundárias

Na Figura 8 estão representados os gráficos de dispersão da concentração de $\mathrm{DBO}$ e da eficiência de remoção de DBO afluente em função da taxa de aplicação hidráulica (TAH) e taxa de aplicação de sólidos (TAS) no decantador secundário.

Foi verificado (Figura 8) que o desempenho das ETEs da modalidade LA não foi afetado por diferentes taxas de aplicação hidráulica no decantador secundário. Mesmo uma ETE que operava em situação de grande sobrecarga (TAH de $15,2 \mathrm{~m}^{3} / \mathrm{m}^{2} . h$, quando o máximo recomendado é de 1,33) apresentou um desempenho típico dessa modalidade de tratamento. A maioria absoluta das ETEs (cerca de 90\%) trabalhava com taxas de aplicação de sólidos (TAS) acima do recomendado, sem que isso tenha se refletido nos resultados.

A Tabela 4 apresenta os valores máximo, médio (em negrito) e mínimo de vazão afluente e do índice de monitoramento apresentados pelas ETEs da modalidade lodos ativados. A Figura 9 mostra as relaçôes entre o desempenho e a vazão e o índice de monitoramento.

Observando-se a Tabela 4 e a Figura 9, nota-se que foi muito grande a diferença entre as vazões tratadas pelas ETEs dessa modalidade, sem que isso interferisse significativamente no desempenho das ETEs. O mesmo foi observado para IM que, apesar da grande amplitude con- siderando o número máximo e mínimo de amostras coletadas, o desempenho não pareceu ter sido afetado.

\section{Reatores UASB}

Para as ETEs correspondentes à modalidade de reatores UASB procurouse verificar a possível existência de melhores resultados de desempenho quando os sistemas trabalhavam numa faixa recomendada para o tempo de detenção hidráulica e velocidade ascensional, como mostrado na Figura 10.

De acordo com a Figura 10, não foram observadas, também no caso dos reatores UASB, influências substanciais dos parâmetros analisados no desempenho dos sistemas. A subcarga hidráulica predominou (TDH bem acima do recomendado), sem que houvesse conseqüências em termos de desempenho.

A Tabela 5 apresenta os valores máximo, médio (em negrito) e mínimo de vazão afluente e do índice de monitoramento apresentados pelos reatores UASB. A Figura 11 mostra as relaçôes entre o desempenho e a vazão e o índice de monitoramento.

$\mathrm{Na}$ Figura 11 pode ser visto que os reatores que tratavam vazões maiores ou que foram considerados mais bem monitorados não tiveram desempenhos superiores aos observados para os outros.
Investigação das causas de desempenhos diferenciados entre ETEs de mesma modalidade de tratamento, considerando a eficiência de remoção de DBO

Um estudo mais aprofundado foi elaborado para determinação das ETEs que apresentaram um desempenho significativamente diferente da média obtida pela modalidade e para verificação de possíveis causas que justificassem tal comportamento. Os testes estatísticos Kruskal Wallis e Tukey foram utilizados para verificar a diferença existente entre os percentuais de eficiência de remoção de DBO entre as ETEs das quatro modalidades de tratamento.

A Tabela 6 apresenta o número total de ETEs em cada uma das modalidades e o número e o percentual de ETEs que tiveram desempenhos significativamente diferentes dos obtidos pela tecnologia de tratamento, de acordo com os testes estatísticos.

As ETEs que foram consideradas atípicas, isto é, com desempenho inferior ou superior à média apresentada pela modalidade, foram avaliadas considerando a influência de fatores de projeto e de operação no seu desempenho. Estas ETEs foram analisadas buscando-se verificar a 

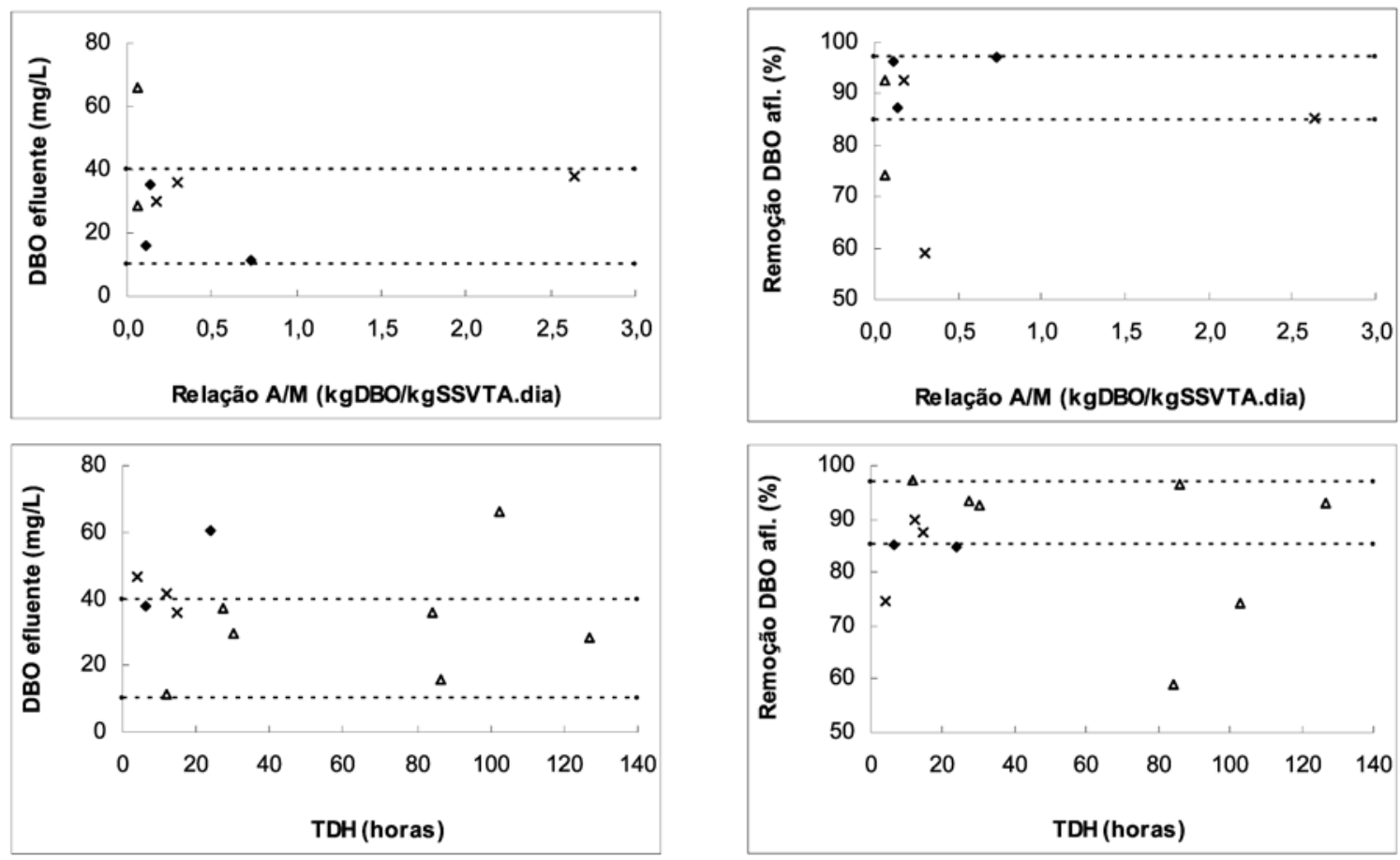

ETEs operando: $\triangle$ Subcarga

Faixa usual $X$ Sobrecarga

Figura 7 - Relação entre rel. A/M, TDH e concentração de DBO efluente e \% de remoção de DBO - Tanques de aeração dos LA
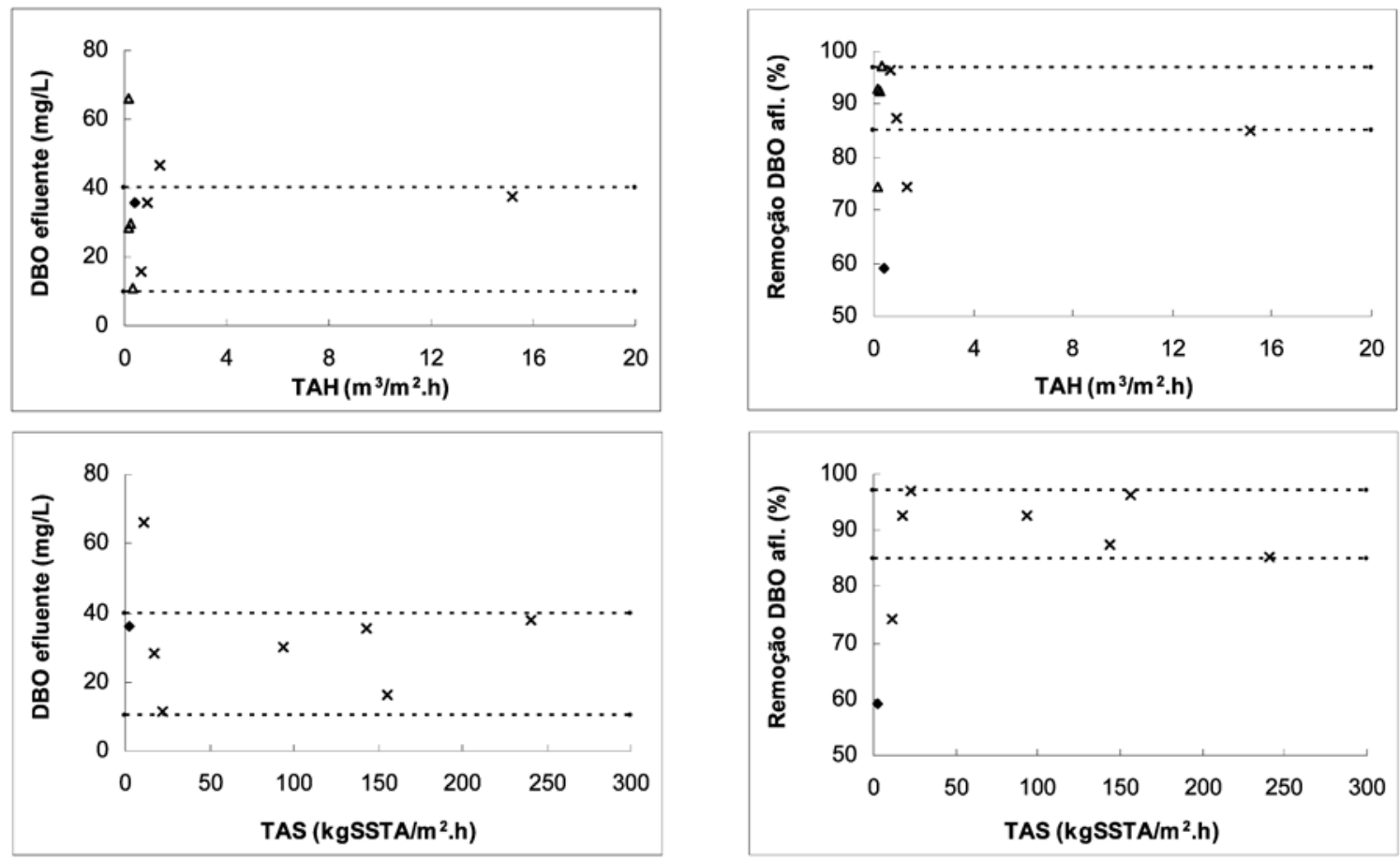

ETEs operando: $\triangle$ Subcarga

Faixa usual $X$ Sobrecarga

Figura 8 - Relação entre TAH, TAS e concentração de DBO efluente e \% de remoção de DBO - Decantadores secundários dos LA 
Tabela 4 - Valores máximos, médios e mínimos de Q afluente e IM - LA

\begin{tabular}{cccc}
\hline Parâmetros & Máximo & Médio & Mínimo \\
\hline Vazões $\left(\mathrm{m}^{3} / \mathrm{dia}\right)$ & 604.800 & $\mathbf{6 3 . 7 1 8}$ & 173 \\
$\mathrm{IM}\left(\mathrm{n}^{\circ}\right.$ amostras/ano) & 157,4 & $\mathbf{3 9 , 6}$ & 0,5 \\
\hline
\end{tabular}
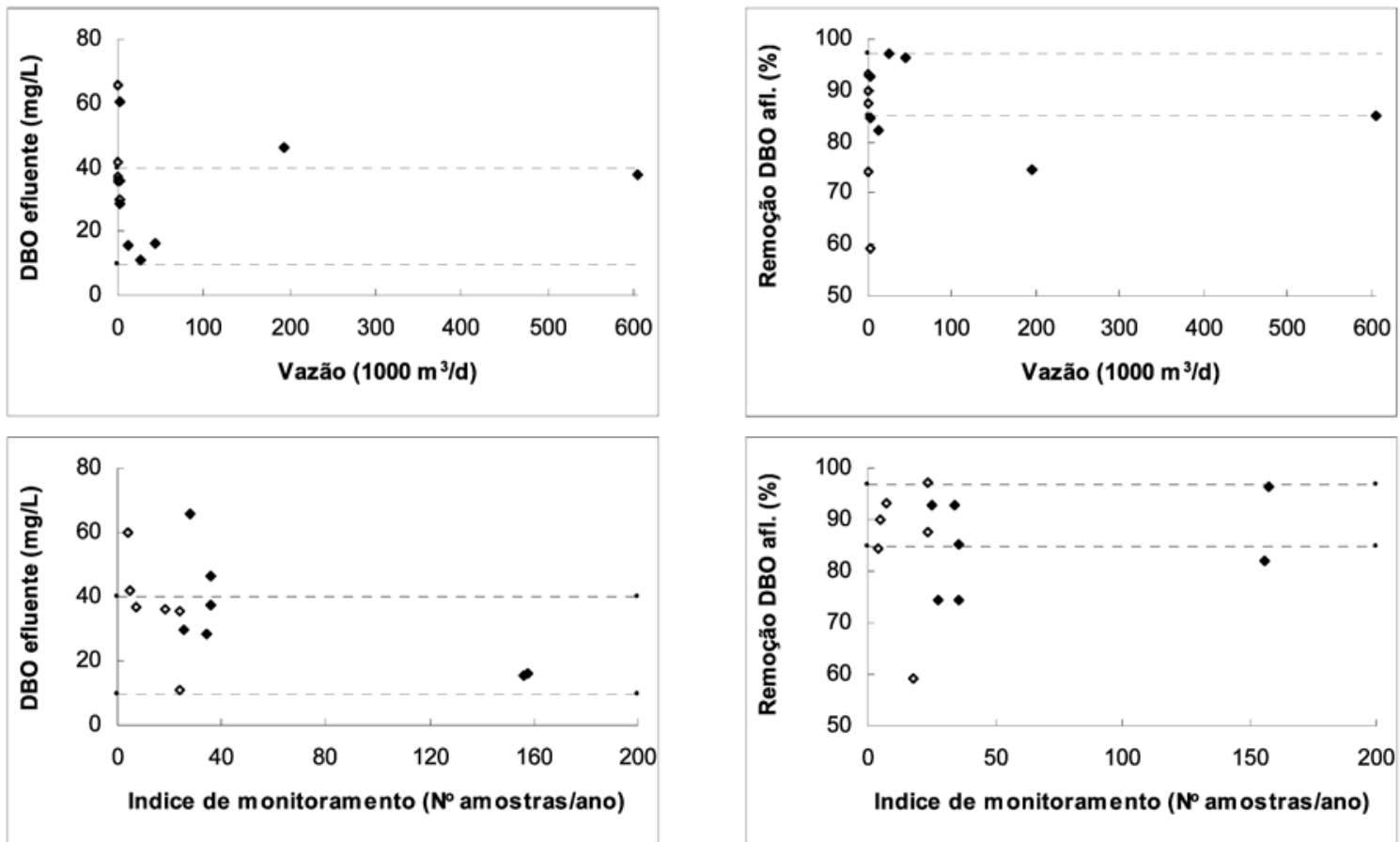

$\diamond$ Percentil $50 \%$ menores

Percentil $50 \%$ maiores

Figura 9 - Relação entre Q e IM e concentração de DBO efluente e \% de remoção de DBO - LA
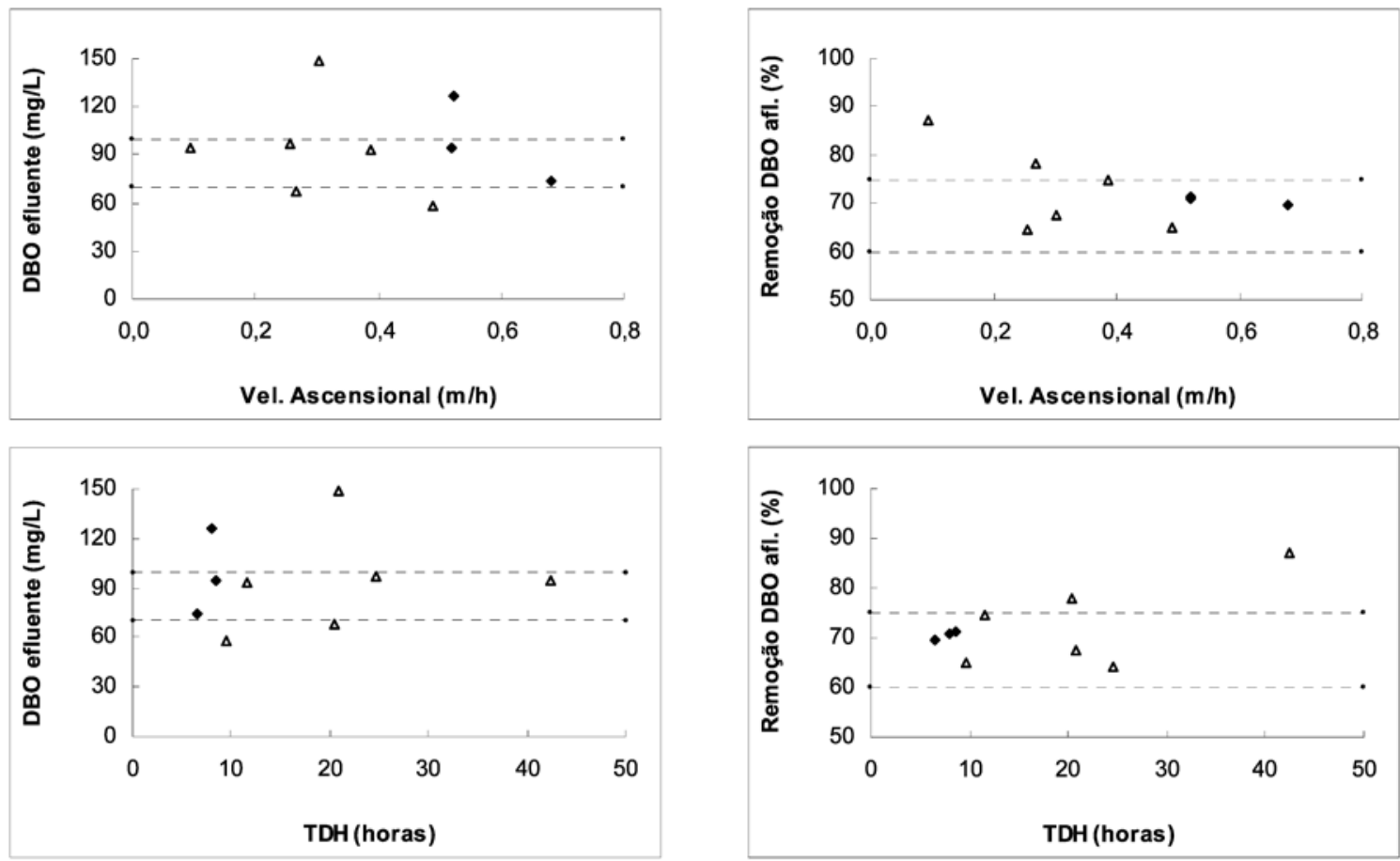

ETES operando: $\triangle$ Subcarga

Faixa usual $X$ Sobrecarga

Figura 10 - Relação entre TDH, Vel. Ascensional e concentração de DBO efluente e \% de remoção de DBO - Reatores UASB 
Tabela 5 - Valores máximos, médios e mínimos de Q afluente e IM - Reatores UASB

\begin{tabular}{cccc}
\hline Parâmetros & Máximo & Médio & Mínimo \\
\hline Vazões $\left(\mathrm{m}^{3} / \mathrm{dia}\right)$ & 17.971 & 3.054 & 40 \\
$\mathrm{IM}\left(\mathrm{n}^{\circ}\right.$ amostras/ano $)$ & 71,6 & 30,1 & 8,8 \\
\hline
\end{tabular}
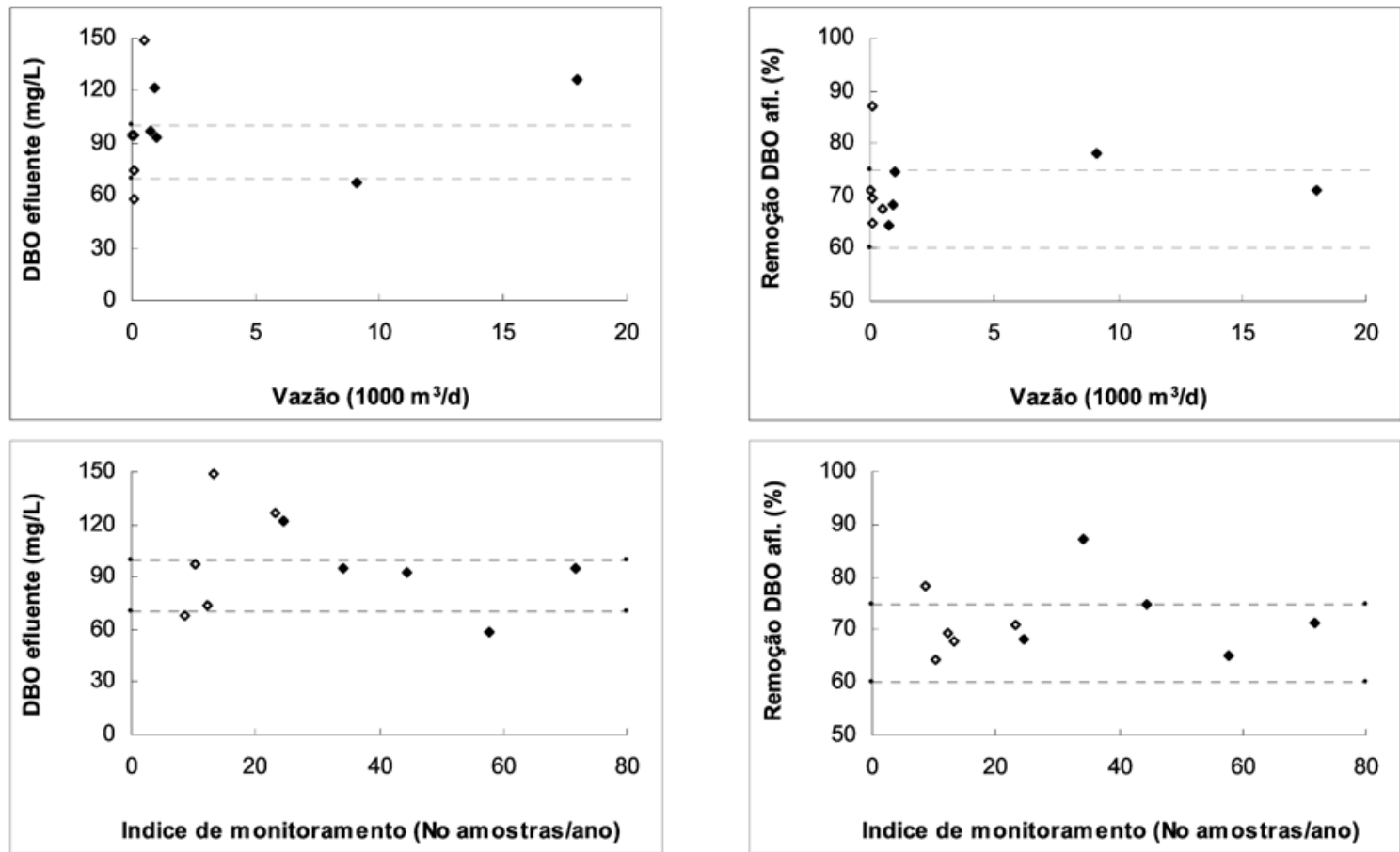

$\checkmark$ Percentil $50 \%$ menores

Percentil $50 \%$ maiores

Figura I I - Relação entre Q e IM e concentração de DBO efluente e \% de remoção de DBO - Reatores UASB

Tabela 6 - ETEs com desempenhos significativamente diferentes, de acordo com os testes estatísticos Kruskal Wallis e Tukey (nível de significância, $\alpha$, de 5\%)

\begin{tabular}{ccccc}
\hline & LA & LF & LAN + LF & UASB \\
\hline Número total de ETEs & 13 & 73 & 43 & 10 \\
Número de ETEs acima da média & 3 & 0 & 3 & 1 \\
Número de ETEs abaixo da média & 6 & 1 & 2 & 1 \\
\% Acima da média da modalidade & 23 & 0 & 7 & 10 \\
\% Abaixo da média da modalidade & 46 & 1 & 5 & 10 \\
\hline
\end{tabular}

existência de melhores resultados de desempenho quando os sistemas trabalhavam numa faixa recomendada para os parâmetros de projeto e operação. A Tabela 7 apresenta as condiçóes de operação das ETEs que se destacaram, positiva ou negativamente, dentro de cada modalidade de tratamento. TB7

Pela observação da Tabela 7, notase que não foi possível estabelecer uma relação consistente entre a eficiência de remoção e as variáveis operacionais. Fo- ram observadas eficiências de remoção acima ou abaixo da média da modalidade para ETEs operando em sobrecarga ou subcarga, indiscriminadamente. A contribuição e a influência de cada variável parece diferir de ETE para ETE e pode ser resultado de projeto, operação ou ambos, como seria de se esperar. Observou-se, ainda, que todas as ETEs que apresentaram percentuais de eficiência de remoção acima da faixa superior reportada pela literatura (von Sperling, 2005) estavam operando fora dos parâmetros usuais de projeto.

\section{CONCLUSÕES}

A influência das condições de carga foi muito pequena e dispersa em todos os processos de tratamento. Observou-se que uma única variável ou um grupo de variáveis não pode ser usada para explicar os desempenhos diferenciados em todas as ETEs. A contribuição e a influência de 
Tabela 7 - Condições de operação das ETEs com desempenhos atípicos dentro das modalidades

\begin{tabular}{|c|c|c|c|c|c|}
\hline \multirow[t]{2}{*}{ Modalidade } & \multirow[t]{2}{*}{ Parâmetro } & \multicolumn{2}{|c|}{$\begin{array}{c}\text { Eficiência média acima } \\
\text { da modalidade }\end{array}$} & \multicolumn{2}{|c|}{$\begin{array}{c}\text { Eficiência média abaixo } \\
\text { da modalidade }\end{array}$} \\
\hline & & $\%$ em sobrecarga & $\%$ em subcarga & $\%$ em sobrecarga & $\%$ em subcarga \\
\hline \multirow[t]{4}{*}{ LA } & Rel. A/M & 0 & 0 & 33 & 17 \\
\hline & $\mathrm{TDH}$ & 0 & 100 & 33 & 33 \\
\hline & TAH & 33 & 33 & 50 & 17 \\
\hline & TAS & 67 & 0 & 50 & 0 \\
\hline \multirow[t]{2}{*}{ LF } & Ls & - & - & 0 & 0 \\
\hline & $\mathrm{TDH}$ & - & - & 0 & 0 \\
\hline \multirow[t]{4}{*}{$\mathrm{LAN}+\mathrm{LF}$} & Ls & 0 & 33 & 50 & 0 \\
\hline & $\mathrm{TDH}$ & 0 & 0 & 0 & 100 \\
\hline & $\mathrm{Lv}$ & 0 & 33 & 0 & 50 \\
\hline & $\mathrm{TDH}$ & 0 & 0 & 0 & 50 \\
\hline \multirow[t]{2}{*}{ UASB } & V. asc. (v) & - & 100 & 0 & 0 \\
\hline & $\mathrm{TDH}$ & - & 100 & 0 & 0 \\
\hline
\end{tabular}

cada variável parece diferir de ETE para ETE e pode ser resultado de projeto, operação ou ambos.

Considerando as condiçôes de operação, não foi observada uma influência expressiva do porte das estações, medida pela vazão afluente, na qualidade do efluente observada. Do mesmo modo, não foi possível determinar uma influência positiva ou negativa da freqüência de monitoramento no desempenho das estações de tratamento, o que leva à reflexão se o IM seria um indicador adequado do nível operacional.

Diante dos resultados, fica evidente que cada ETE deve ser avaliada individualmente para se tentar justificar bons ou maus desempenhos, já que estes são decorrentes de fatores diversos. É necessário, por parte do projetista e do operador, um conhecimento aprofundado e integrado de cada sistema, envolvendo não apenas as cargas hidráulica e orgânica aplicadas, mas também fatores nem sempre diretamente mensuráveis. Características específicas de cada afluente, aspectos microbiológicos nos reatores, aspectos hidráulicos nas estruturas de entrada, saída e transferência, zonas mortas, curtoscircuitos hidráulicos, condições de funcionamento dos equipamentos eletromecânicos, além de detalhes de projeto, construção e manutenção, devem ser analisados de maneira conjunta, para se tentar estabelecer e entender as várias inter-relações existentes em uma estação de tratamento de esgotos.

\section{AGRADECIMENTOS}

USP, FINEP, SABESP, COPASA, FEAM, Fapemig e CNPq e prestadores de serviços municipais.

\section{REFERÊNCIAS}

CHERNICHARO, C.A.L, Reatores anaeróbios. 1.ed. Belo Horizonte: Departamento de Engenharia Sanitária e Ambiental da UFMG, 245 p. (Princípio do tratamento biológico de águas residuárias, 5). 1997.

CRITES, R., TCHOBANOGLOUS, G. Tratamiento de aguas residuales en pequeñas poblaciones. Bogotá, Colombia: Mcgraw-Hill Interamericana S.A., 776 p. 2000.

METCALF \& EDDY. Wastewater engineering: treatment, and reuse. New York: Metcalf \& Eddy, Inc., 4 th. Ed., 1819p. 2003.

NIKU, S. SCHROEDER, E.D., SAMANIEGO F.J. Performance of activated sludge process and reliability-based design. Journal Water Pollution Control Association, v. 51, n. 12, p. 2841 - 2857, Dec., 1979.

NIKU, S., SCHROEDER, ED., TCHOBANOGLOUS, G., SAMANIEGO F.J. Performance of activated sludge process: reliability, stability and variability. Environmental Protection Agency, EPA Grant $\mathrm{N}^{\circ}$ R805097-01, pp. 1 - 124. 1981.

NIKU, S., CHROEDER, E.D., HAUGH, R.S. Reliability and stability of trickling filter processes. Journal Water Pollution Control Association, v. 54, n. 2, p. 129 - 134, Feb. 1982.

NIKU, S., SCHROEDER, E.D. Factors affecting effluent variability from activated sludge processes. Journal Water Pollution Control Association, v. 53, n. 5, p. 546 - 559, May, 1981.
OLIVEIRA, S.M.A.C.; VON SPERLING, M. Avaliação de 166 ETEs em operação no país, compreendendo diversas tecnologias. Parte 1. Análise de desempenho. Engenharia Sanitária e Ambiental (ABES), 2005.

VON SPERLING, M. Lagoas de estabilização. Belo Horizonte: DESA - UFMG, 196p. (Princípios do tratamento biológico de águas residuárias, 3). 2002.

VON SPERLING, M. Lodos ativados. Departamento de Engenharia Sanitária e Ambiental UFMG, 415p. (Princípios do tratamento biológico de águas residuárias, 4). 1997.

VON SPERLING, M. Principios do tratamento biológico de águas residuárias. Vol. 1. Introdução à qualidade das águas e ao tratamento de esgotos. Departamento de Engenharia Sanitária e Ambiental - UFMG. $3^{\text {a }}$ ed. 456 p. 2005.

VON SPERLING, M., CHERNICHARO, C.A.L. A comparison between wastewater treatment processes in terms of compliance with effluent quality criteria standards. In: XXVII CONGRESO INTERAMERICANO DE INGENIERIA SANITARIA Y AMBIENTAL, 2000, Porto Alegre. Anais...Porto Alegre: AIDIS, 2000.

VON SPERLING, M., CHERNICHARO, C.A.L. Urban wastewater treatment technologies and the implementation of discharge standards in developing countries. Urban Water, v. 4. p. 105-114, 2002

Endereço para correspondência:

Marcos von Sperling

DESA - Universidade Federal de

Minas Gerais

Av. Contorno 842 - $7^{\circ}$ andar

30I I0-060-BeloHorizonte-MG-Brasil

Tel:(3I)3238-1935- Fax.(3I) 3238-1879

E-mail: marcos@desa.ufmg.br 